TABLE II

\begin{tabular}{r|l|l|l|l|l}
\hline 1 & $6 / 90$ & $5 / 60$ & 11 & $6 / 120$ & $3 / 60$ \\
2 & $6 / 90$ & $5 / 60$ & 12 & $6 / 120$ & $3 / 60$ \\
3 & $6 / 90$ & $5 / 60$ & 11 & $6 / 120$ & $2 / 60$ \\
& $6 / 90$ & $5 / 60$ & 12 & $6 / 120$ & 260 \\
5 & $6 / 90$ & $4 / 60$ & 13 & $6 / 150$ & $3 / 60$ \\
6 & $6 / 90$ & $4 / 60$ & 14 & $6 / 150$ & $3 / 60$ \\
7 & $6 / 90$ & $4 / 60$ & 15 & $6 / 150$ & $3 / 60$ \\
8 & $6 / 90$ & $4 / 60$ & 17 & $6 / 150$ & $2 / 60$ \\
10 & $6 / 90$ & $3 / 60$ & 18 & $6 / 150$ & $2 / 60$ \\
13 & $6 / 90$ & $3 / 60$ & 20 & $6 / 150$ & $1 / 60$ \\
16 & $6 / 90$ & $3 / 60$ & 19 & $6 / 180$ & $2 / 60$ \\
4 & $6 / 120$ & $5 / 60$ & 20 & $6 / 180$ & $1 / 60$ \\
9 & $6 / 120$ & $4 / 60$ & 22 & $6 / 180$ & $1 / 60$ \\
\hline
\end{tabular}

As regards the occasions when this type for more than $6 / 60$ will be needed each oculist must decide for himself, but I suggest that it should always be used in schools for the partially-sighted, whether myopes or not, also in such cases as those which require an accurate report of their vision. I hope that possibly this suggestion may be of some use in helping to solve the difficult problem of deciding if a patient is " blind." At present the definition of blindness is vague, and perhaps the addition of an accurate record of vision together with the usual " so blind as to be unable to perform any work for which eysight is essential" may be of assistance.

\title{
ANNOTATION
}

\section{Quis Custodiet Ipsos Custodes}

When a patient begins to cross-examine one about some part of his ophthalmic anatomy, before one has mentioned it, it is a sure sign that he has been told something by somebody else and wishes to have a second opinion without disclosing the fact that he has already had a previous one. If one realises at the time what he is at, it is best to tell the patient to put all his cards on the table. But many patients love being secretive; they do not necessarily wittingly mislead one but they like to keep facts back. The writer was taken in in this way some years ago and the story may be worth telling. A young man was sent to see us by a doctor who had been our contemporary as a student. He complained of his right eye which had become misty about 4 days before. The eye was only 
slightly injected and there was a quite obvious crop of keratic precipitates in the lower part of the cornea. The vision was roughly $6 / 18$ and the tension not raised, there were no synechiae present. After having dilated the pupil it was difficult to get a clear view of the fundus; the disc appeared normal but the lower branch of the central vein was markedly dilated. The field showed a large quadrantic defect which ran in to the blind spot. We judged that there was a patch of choroiditis somewhere and finding that pus was exuding from a sinus in connexion with one of the teeth in his upper jaw we suggested this as a possible cause, advised him to see his dentist without delay and promised to communicate with our doctor friend. Then it was that he began to cross-examine us about his optic nerve. We did not realize the reason until two days later when another doctor rang us up and explained that he had previously sent the patient to his own oculist who had diagnosed optic neuritis and had urged institutional treatment. The doctor seemed quite hurt: "so-and-so says he's got optic neuritis, you say he hasn't, which am I to believe?" This was a ticklish question but after a little talk it was settled that the patient should be returned to the first oculist and that we should meet him there in consultation. Of course the man was late for his appointment and while waiting my colleague told me that he had not found the precipitates and I confessed to not having seen a patch of choroiditis, thơugh I had suspected it. Both precipitates and a choroidal patch were quite obvious when he at length arrived. When, some time after, we met our colleague we asked what had happened to this man. "Oh," said he, "he went off to see a third man, one of our clinical assistants at the hospital, and he said he could find nothing the matter with the eyes at all."

When the seniors make an error how shall we blame the clinical assistants?

\section{ABSTRACTS}

\section{MEDICAL OPHTHALMOLOGY}

(1) Good, P. (Oak Park, Illinois). - Choked discs in lead encephalopathy. Amer. Jl. Ophthal., Vol. XXIV; p. 794, 1941.

(1) Good states that lead poisoning usually occurs in children 1 to 3 years of age and the chief source is paint on cribs and toys. In some cases nipple shields have been blamed. A blood concentration of lead below $0.03 \mathrm{mg}$. per 100 c.c. is normal and over 0.06 